\title{
Novel unbiased equations to calculate triglyceride-rich lipoprotein cholesterol from routine non-fasting lipids
}

\author{
Michel P Hermans ${ }^{1,3^{*}}$, Sylvie A Ahn ${ }^{2}$ and Michel F Rousseau ${ }^{2}$
}

\begin{abstract}
Background: Non-fasting triglyceride-rich lipoproteins cholesterol (TRL-C) contributes to cardiovascular risk, in that it includes remnant cholesterol (RC). TRL-C is computed as total $C-[L D L-C+H D L-C]$. Such calculation applies only if LDL-C is directly measured, or obtained from a non-Friedewald's formula, a method as yet never benchmarked against independent markers of TRL burden.

Methods: The Discriminant Ratio (DR) methodology was used in 120 type 2 diabetic patients in order: (i) to compute TRL-C from non-fasting lipids; (ii) to establish the performance of TRL-C and TRL-C/apoA-I (vs. TG-based markers) to grade TRLs and atherogenic dyslipidemia (AD); and (iii) to relate TRL-C with non-fasting TG.

Results: Depending on apoB 100 availability, TRL-C (mg/dL) can be derived from non-fasting lipids in two ways: (a) total cholesterol (TC) - [(0.0106* TC - 0.0036* TG + 0.017* apoB $100-0.27) * 38.6]-\mathrm{HDL}-\mathrm{C}$; and (b) TC - [(0.0106* TC $0.0036 * \mathrm{TG}+0.017 *[0.65 *(\mathrm{TC}-\mathrm{HDL}-\mathrm{C})+6.3]-0.27) * 38.6]-\mathrm{HDL}-\mathrm{C}$. Discrimination between log TG] and TRL-C was similar (DR 0.94 and 0.84, respectively), whereas that of $\log [\mathrm{TG}] / \mathrm{HDL}-\mathrm{C}$ was better than TRL-C/apoA-I (DR 1.01 vs. 0.65; $p$ 0.0482). All Pearson's correlations between pairs reached unity, allowing formulation of two unbiased equivalence equations: (a) TRL-C $=97.8 * \log [\mathrm{TG}]-181.9$; and (b) TRL-C/apoA-I $=8.15 *(\log [\mathrm{TG}] / \mathrm{HDL}-\mathrm{C})-0.18$.

Conclusions: TRL-C and log $[\mathrm{TG}]$ are as effective and interchangeable for assessing remnant atherogenic particles. For grading TRL-AD, it is best to use $\log [T G] / H D L-C$, inherently superior to TRL-C/apoA-I, while measuring the same underlying variable.
\end{abstract}

Keywords: Remnant cholesterol, Triglycerides, Non-fasting, Chylomicrons, Lipoprotein, Diabetes, Atherogenic dyslipidemia

\section{Introduction}

Cholesterol $(\mathrm{C})$ in atherogenic particles other than lowdensity lipoproteins (LDL) is an emerging risk factor (RF) for ischemic heart disease, and is mostly found in fasting and non-fasting triglyceride-rich lipoproteins (TRLs). TRLs comprise two clusters: (i) chylomicrons (CM; triglycerides (TG)-rich lipoproteins (TRLs) of intestinal origin) and their remnants (CMR), each carrying

\footnotetext{
* Correspondence: michel.hermans@diab.ucl.ac.be

${ }^{1}$ Division of Endocrinology \& Nutrition, Cliniques universitaires St-Luc and Institut de Recherche Expérimentale et Clinique (IREC), Université catholique de Louvain, Brussels, Belgium

${ }^{3}$ DipNatSci DipEarthSci DipGeogEnv PGCert (SocSc), Endocrinology \&

Nutrition, UCL 54.74 Tour Claude Bernard +1, avenue Hippocrate 54, Brussels B-1200, Belgium

Full list of author information is available at the end of the article
}

one apolipoprotein (apo) $\mathrm{B}_{48}$ ); and (ii) very-low density lipoproteins (VLDL; endogenous TRLs which originate in the liver, and their relatively TG-depleted remnants (VLDL-R), each carrying one apoB $B_{100}$ ) [1-13].

Table 1 describes the distribution of fasting and nonfasting lipid particles, TRLs, and TRL remnants distribution, with respective contribution to total cholesterol, TRL-cholesterol (TRL-C), and TRL-remnant cholesterol (TRL-RC), alongside their major corresponding apolipoprotein(s). Among TRLs, nonfasting residual TG-rich particles are considered as a major contributor to residual vascular risk (RVR), even in patients on statins whose LDL-C reaches target. These residual lipoproteins are a blend of chylomicrons remnants (CM-R) and very-low-density lipoprotein remnants (VLDL-R). Their 
Table 1 Fasting and nonfasting lipid particles, triglyceride-rich lipoproteins (TRL), and TRL remnants distribution, with respective contribution to total cholesterol, TRL-cholesterol and TRL-remnant cholesterol, alongside major corresponding apolipoprotein(s)

\begin{tabular}{|c|c|c|c|c|c|}
\hline \multicolumn{3}{|c|}{ Fasting } & \multicolumn{3}{|c|}{ Nonfasting } \\
\hline All lipoproteins & Total cholesterol & Apolipoprotein(s) & All lipoproteins & Total cholesterol & Apolipoprotein(s) \\
\hline$(C M-R)$ & $(C M-R-C)$ & $\left(\mathrm{apoB}_{48}\right)$ & $C M$ & $\mathrm{CM}-\mathrm{C}$ & $\mathrm{apoB}_{48}$ \\
\hline VLDL & VLDL-C & $\mathrm{apoB}_{100}$ & $C M-R$ & $C M-R-C$ & $\mathrm{apoB}_{48}$ \\
\hline VLDL-R & VLDL-R-C & $\mathrm{apoB}_{100}$ & VLDL & VLDL-C & $\mathrm{apoB}_{100}$ \\
\hline $\mathrm{IDL}$ & IDL-C & $\mathrm{apoB}_{100}$ & VLDL-R & VLDL-R-C & apoB $B_{100}$ \\
\hline LDL & LDL-C & $\mathrm{apoB}_{100}$ & $\mathrm{IDL}$ & $\mathrm{IDL}-\mathrm{C}$ & $\mathrm{apoB}_{100}$ \\
\hline $\mathrm{HDL}$ & $\mathrm{HDL}-\mathrm{C}$ & apoA-l; apoA-II & LDL & LDL-C & $\mathrm{apoB}_{100}$ \\
\hline \multirow[t]{2}{*}{ Lipoprotein(a) } & Lipoprotein(a)-C & $a_{p o B} 100 ;$ apo(a) & $\mathrm{HDL}$ & $\mathrm{HDL}-\mathrm{C}$ & apoA-l; apoA-II \\
\hline & & & Lipoprotein(a) & Lipoprotein(a)-C & $\mathrm{apoB}_{100 ;} ; \mathrm{apo}(\mathrm{a})$ \\
\hline TRLs & TRL-cholesterol & Apolipoprotein(s) & TRLs & TRL-cholesterol & Apolipoprotein(s) \\
\hline$(C M-R)$ & (CM-R-C) & $\left(\mathrm{apoB}_{48}\right)$ & $C M$ & CM-C & $\mathrm{apoB}_{48}$ \\
\hline VLDL & VLDL-C & $\mathrm{apoB}_{100}$ & $C M-R$ & $C M-R-C$ & $\mathrm{apoB}_{48}$ \\
\hline \multirow[t]{2}{*}{ VLDL-R } & VLDL-R-C & $\mathrm{apoB}_{100}$ & VLDL & VLDL-C & $a p o B_{100}$ \\
\hline & & & VLDL-R & VLDL-R-C & $\mathrm{apoB}_{100}$ \\
\hline TRL remnants & TRL-remnant cholesterol & Apolipoproteins(s) & TRL remnants & TRL-remnant cholesterol & Apolipoprotein(s) \\
\hline$(C M-R)$ & $(C M-R-C)$ & $\left(a_{p o B}\right)$ & $C M-R$ & $C M-R-C$ & $\mathrm{apoB}_{48}$ \\
\hline VLDL-R & VLDL-R-C & $\mathrm{apoB}_{100}$ & VLDL-R & VLDL-R-C & $\mathrm{apoB}_{100}$ \\
\hline
\end{tabular}

apo apolipoprotein, $C$ cholesterol, $C M$ chylomicron $C M-R$ chylomicron remnant, $H D L$ high-density lipoprotein, IDL intermediate-density lipoprotein, $L D L$ low-density lipoprotein, $T R L$ triglyceride-rich lipoprotein, $V L D L$ very-low density lipoprotein, $V L D L-R$ very-low density lipoprotein remnant; parentheses refer to very low presence.

atherogenicity is related to their ability to deliver cholesterol in vessels walls.

Quantification of the cholesterol content of TG-rich particles would be informative to better characterize their nonfasting atherogenic load. However this would require direct specific lipoproteins measurement beyond routine clinical practice. For this reason, several authors recently proposed to use a simple formula to measure "remnant cholesterol" (RC) from standard nonfasting lipids, "RC" being calculated as total C - (high-densitylipoprotein (HDL)-C + LDL-C) $[10,11]$. Such equation however measures TRL-C (the sum of CM-C, CMR-C, VLDL-C and VLDL-R-C), and not RC. The latter is the sum of CMR-C and VLDL-R-C, and accounts for only two out of four components of TRL-C (Table 1).

As for RC, non-fasting TRL-C is usually not measured, but derived according to the formula set out above: TRL$\mathrm{C}=$ total $\mathrm{C}$ minus [LDL-C + HDL-C] [8-11]. Whereas LDL-C can be inferred from Friedewald's equation in fasting conditions, this calculation underestimates LDL-C in moderate to severe hypertriglyceridemia (200-400 mg/dL), and is inapplicable for fasting TG $>400 \mathrm{mg} / \mathrm{dL}$ [14]. To overcome this inaccuracy, a novel method for estimating LDL-C from standard lipid profile using an adjustable factor for the TG:VLDL-C ratio was recently proposed by Martin et al. $[15,16]$.

By its very nature, Friedewald's equation is unusable in the non-fasting state. This is because in the presence of elevated fasting TG or in non-fasting conditions, the C-to-TG content of remnant lipoproteins (RLPs) infringes the steady $1 / 5$ ratio ( $20 \% \mathrm{C}$ and $80 \% \mathrm{TG}$ ) at the core of Friedewald's method [14-20]. Determining nonfasting TRL-C using a Friedewald-derived LDL-C level is methodologically inadequate, as it merely equates TRL-C with one-fifth of non-fasting TG, thus failing to provide additional information beyond TG levels $[8,10,11]$.

The lack of a simple and suitable method to determine TRL-C currently limits its clinical use for evaluating RVR, unless adequate alternatives to determine nonfasting LDL-C are used. To circumvent this difficulty, an alternative approach is to derive $\mathrm{LDL}-\mathrm{C}$ from $\mathrm{apoB}_{100}$, waiving the bias generated by applying a fixed $\mathrm{C}$-to-TG ratio that assumes constant and identical composition for all RLPs. A disadvantage of this method is the requirement for direct apo $B_{100}$ measurement, limiting its use unless apo $B_{100}$ is inferred from routine lipids, as previously described [17-21].

The aims of this study were: (i) to provide relevant equations to estimate TRL-C from non-fasting lipids, regardless $\mathrm{apoB}_{100}$ availability; (ii) to establish the performance and equivalence of TG-based markers $v s$. TRL-C and TRL-C/apoA-I, a continuous estimator of atherogenic dyslipidemia (AD); and (iii) to derive an unbiased equation predicting TRL-C from non-fasting TG. We used the Discriminant Ratio (DR) methodology which standardizes comparisons between measurements 
by taking into account fundamental properties for assessing imprecision and practical performance of tests designed to quantify similar variables $[19,22,23]$.

\section{Methods}

We studied 120 consecutive (86\% white Caucasians) patients with T2DM, treated or not with lipid-lowering drug(s) (LLD). Age; gender; diabetes duration; smoking history; anthropometric indices; hypertension and metabolic syndrome (MetS) prevalence, the latter defined according to the harmonized criteria of Alberti et al. [24]; habitual ethanol intake; current glucose-lowering drugs, and LLDs were analysed. Hypertension was defined as systolic $\geq 140$ and/or diastolic blood pressure $\geq 90 \mathrm{mmHg}$, and/or treatment with antihypertensive drugs. Glomerular filtration rate was estimated (eGFR) using the Modification of Diet in Renal Disease formula [25]. Albuminuria was defined as an albumin excretion $\geq 30 \mu \mathrm{g} . \mathrm{mg}$ creatinine $^{-1} .1 .73 \mathrm{~m}^{2}$ from first-morning sample. Coronary and peripheral artery disease (CAD and PAD) were diagnosed as in [26], while stroke was defined according to UK Prospective Diabetes Study (UKPDS) criteria [27]. Atherogenic dyslipidemia (AD) was defined according to [28-30].

The following variables were measured in the nonfasting state: glycated haemoglobin $\left(\mathrm{HbA}_{1 \mathrm{c}}\right)$, total $\mathrm{C}$; HDL-C; TG; apoA-I and apoB ${ }_{100}$, with total C and TG determined with SYNCHRON system (Beckman Coulter Inc., Brea, CA); HDL-C with ULTRA-N-geneous reagent (Genzyme Corporation, Cambridge, MA); apoA-I and $\mathrm{apoB}_{100}$ by immunonephelometry (BNII Analyzer, Siemens Healthcare Products GmbH, Marburg, Germany). Nonfasting routine lipids, apoA-I and $\mathrm{apoB}_{100}$ were measured on two non-consecutive days for DR calculation, with a 4-6 months' interval between samples. A non$\mathrm{HDL}-\mathrm{C} / \mathrm{apoB}_{100}$ ratio $>2.6$ was an exclusion criterion because highly suggestive for Type III hyperlipoproteinemia [31]. The within-subjects coefficients of variation were: 5.4\% [total C]; 7.1\% [HDL-C]; 4.9\% (apoA-I) and 6.9\% $\left[\mathrm{apoB}_{100}\right]$.

TRL-C was calculated from non-fasting lipids by subtracting [LDL-C + HDL-C] from total C, with LDL-C computed using Planella's formula $[17,19]$ :

$$
\begin{aligned}
\mathbf{L D L}-\mathbf{C}(\mathrm{mmol} / L)= & 0.41 * \mathbf{T C}(\mathrm{mmol} / L)-0.32 \\
& * \mathbf{T G}(\mathrm{mmol} / L)+1.7 \\
& * \mathbf{a p o B}_{\mathbf{1 0 0}}(g / L)-0.27
\end{aligned}
$$

Normal TRL-C values from 50 apparently-healthy lean Caucasians, untreated with LLD and without familial hypercholesterolemia or early-onset parental CV disease, were $(m g / d L)$ : 24 (mean); 21 (median); $17(S D) ; 2$ (minimum); 71 (maximum); 13 (percentile 25) and 29 (percentile 75$)$.
Each patient gave written informed consent; the study was performed in agreement with Helsinki's Declaration; Good Clinical Practice principles; and the local Institutional Review Board.

\section{Statistics}

The Discriminant Ratio (DR) methodology compares different tests measuring the same underlying physiological variable by determining the ability of a test to discriminate between different subjects, and the comparison of discrimination between different tests as well as the underlying correlation between pairs of tests adjusting for attenuation due to within-subject variation [22]. In a comparison study where duplicates measurements are performed in each subject, the measured between-subject standard deviation $\left(\mathrm{SD}_{\mathrm{B}}\right)$ is calculated as the $\mathrm{SD}$ of the subject mean values calculated from the 2 replicates.

- The standard mathematical adjustment to yield the underlying between-subject $\mathrm{SD}\left(\mathrm{SD}_{\mathrm{U}}\right)$ is: $\mathrm{SD}_{\mathrm{U}}=$ $\sqrt{ }\left(\mathrm{SD}_{\mathrm{B}}^{2}-\mathrm{SD}_{\mathrm{W}}^{2} / 2\right)$

- The within-subject variance $\left(\mathrm{V}_{\mathrm{w}}\right)$ calculated (for $m$ repeat tests) as $\left.\left(\mathrm{V}_{\mathrm{w}}\right)=\Sigma\left(\mathrm{x}_{\mathrm{j}}-\mathrm{x}_{\mathrm{i}}\right)^{2} /(\mathrm{m}-1)\right)$, the within-subject $\mathrm{SD}\left(\mathrm{SD}_{\mathrm{w}}\right)$ being its square root;

- The DR represents the ratio $\mathrm{SD}_{\mathrm{U}} / \mathrm{SD}_{\mathrm{W}}$

Confidence limits for DR's and the testing for equivalence of different DR's were calculated and differences were considered significant for $p<0.05$. Given sample size and number of replicates, the minimal detectable significant difference in DR for the present study was 0.42. Coefficients of correlation between pairs of tests (measured $v s$. estimated) were adjusted to include an estimate of the underlying correlation, as standard coefficients tend to underestimate the true correlation between tests, due to within-subject variation [22].

Results are presented as means $( \pm 1$ standard deviation [SD]), or as proportions (\%). The significance of differences between means was assessed by Student's $t$ test, or by Welch's test for data sets with significant differences in SDs, and by $\mathrm{Chi}^{2}$ test for differences in proportions. Results were considered statistically significant or nonsignificant (NS) for $p<0.05$ or $p \geq 0.05$, respectively.

\section{Results}

Patients' characteristics are described in Table 2. Mean age (1 SD) was 67 (11) years, with a male gender predominance. Mean body mass index was in the overweight range. Patients had long-standing diabetes (mean duration 16 (9) years), with a majority also having hypertension (89\%), and a MetS phenotype (92\%). Current smokers amounted to 13\%; habitual ethanol intake was 10 (18) U/week. Mean glycaemic control, as reflected by $\mathrm{HbA}_{1 \mathrm{c}}$, was suboptimal at $7.79(1.32) \%(62(10) \mathrm{mmol} /$ 
Table 2 Patients' characteristics

\begin{tabular}{|c|c|c|}
\hline$n$ & & 120 \\
\hline Age & Years & $67(11)$ \\
\hline Diabetes duration & Years & $16(9)$ \\
\hline Male: female & $\%$ & 63: 37 \\
\hline Smoking $^{\S}$ & & $42-45-13$ \\
\hline Body mass index & $\mathrm{kg} \cdot \mathrm{m}^{-2}$ & $30.2(5.6)$ \\
\hline Waist circumference & $\mathrm{cm}$ & $106(15)$ \\
\hline Metabolic syndrome & $\%$ & 92 \\
\hline Hypertension & $\%$ & 89 \\
\hline Anti-dyslipidemic drug(s) & $\%$ & 92 \\
\hline Statin-fibrate-ezetimibe & $\%$ & $81-38-12$ \\
\hline $\mathrm{HbA}_{1 \mathrm{c}}$ & $\%$ & $7.79(1.32)$ \\
\hline $\mathrm{HbA}_{1 \mathrm{c}}$ & $\mathrm{mmol} \cdot \mathrm{mol}^{-1}$ & $62(10)$ \\
\hline Glomerular filtration rate & $\mathrm{mL} \cdot \mathrm{min}^{-1} 1.73 \mathrm{~m}^{2}$ & $73(27)$ \\
\hline Albuminuria & $\mu g \cdot m g$ creatinine ${ }^{-1}$ & $90(240)$ \\
\hline Atherogenic dyslipidemia & $\%$ & 58 \\
\hline Total cholesterol & $m g \cdot d L^{-1}$ & $172(34)$ \\
\hline Non-HDL-C & $m g \cdot d L^{-1}$ & $127(33)$ \\
\hline LDL-C & $m g \cdot d L^{-1}$ & $91(26)$ \\
\hline TRL-C & $m g \cdot d L^{-1}$ & $36(20)$ \\
\hline TG & $m g \cdot d L^{-1}$ & $197(101)$ \\
\hline $\log [\mathrm{TG}]$ & $m g \cdot d L^{-1}$ & $2.23(0.20)$ \\
\hline $\mathrm{apoB}_{100}$ & $m g \cdot d L^{-1}$ & $89(21)$ \\
\hline apoA-I & $m g \cdot d L^{-1}$ & $145(25)$ \\
\hline $\mathrm{HDL}-\mathrm{C}$ & $m g \cdot d L^{-1}$ & $44(12)$ \\
\hline $\log [\mathrm{TG}] / \mathrm{HDL}-\mathrm{C}$ & & $0.057(0.024)$ \\
\hline TRL-C/apoA-I & & $0.28(0.20)$ \\
\hline Macroangiopathy & $\%$ & 33 \\
\hline Coronary artery disease & $\%$ & 23 \\
\hline Peripheral artery disease & $\%$ & 11 \\
\hline Transient ischemic attack/stroke & $\%$ & 7 \\
\hline
\end{tabular}

Results are expressed as means (1 SD) or proportions, with nonfasting lipids and lipoproteins values representing the means of Day 1 and Day 2. Apo apolipoprotein, $\mathrm{C}$ cholesterol, $H b A_{1 c}$ glycated haemoglobin, $H D L$ high-density lipoprotein, $L D L$ low-density lipoprotein, TG trigylycerides, TRL TG-rich lipoprotein; ${ }^{\S}$ never-former-current.

mol). Overall microangiopathy prevalence was 58\%: retinopathy $37 \%$; polyneuropathy $28 \%$ and/or (micro) albuminuria $29 \%$.

Most patients were on LLDs: statins (81\%) and/or fibrates (38\%). Current mean lipids and lipoproteins values were illustrative of patients with the usual form of T2DM, i.e. associated with central adiposity, insulin resistance (IR) and MetS: low HDL-C with raised nonHDL-C, apoB $B_{100}$, TG and TRL-C, together with a high prevalence of $\mathrm{AD}(58 \%)$. Overall macroangiopathy prevalence was 33\%: CAD [23\%]; PAD [11\%] and/or cerebrovascular disease $[7 \%]$.
Figure 1 shows the plots of untransformed values on two different days for TG; TRL-C; $\log [\mathrm{TG}] / \mathrm{HDL}-\mathrm{C}$; and TRL-C/apoA-I, respectively. Relative median day-to-day variations were: $36 \%$ (TG); 39\% (TRL-C); $16 \%(\log [\mathrm{TG}] /$ HDL-C); and 46\% (TRL-C/apoA-I), respectively. Figure 1 also shows the heteroscedastic arrangement of the data spread on repeat measurements.

The precision, discrimination and interrelation of each non-fasting estimate, expressed as underlying betweensubject standard deviation $\left(\mathrm{SD}_{\mathrm{u}}\right)$, global within-subject standard deviation $\left(\mathrm{SD}_{\mathrm{w}}\right)$, discriminant ratio $(\mathrm{DR})$; and measured Pearson's product-moment correlation coefficients are shown in Table 3. For the $\log [\mathrm{TG}]$ vs. TRL-C comparison, the respective $\mathrm{SD}_{\mathrm{u}} / \mathrm{SD}_{\mathrm{w}}$ (DRs) were 0.94 and 0.84 , and the difference in discriminatory power between the two determinations did not reach statistical significance. As regards the $\log [\mathrm{TG}] / \mathrm{HDL}-\mathrm{C}$ vs. TRL-C/ apoA-I comparison, the respective DRs were 1.01 and 0.65 , the discriminatory power of $\log [\mathrm{TG}] / \mathrm{HDL}-\mathrm{C}$ being significantly better than of TRL-C/apoA-I ( $p$ 0.0482).

The Pearson's correlations between each pair of tests were high, respectively $0.92(\log [\mathrm{TG}]$ vs. TRL-C) and $0.89(\log [\mathrm{TG}] / \mathrm{HDL}-\mathrm{C}$ vs. TRL-C/apoA-I), each correlation reaching unity, once values were adjusted for attenuation prior to correlation (Table 3).

Figure 2 shows the plots of untransformed values (means of Day 1 and Day 2) for $\log [\mathrm{TG}] v s$. TRL-C, and $\log [\mathrm{TG}] / \mathrm{HDL}-\mathrm{C}$ vs. TRL-C/apoA-I. The equations of the unbiased lines of equivalence relating each pair of tests were:

$$
\begin{aligned}
& \text { TRL-C }(m g / d L)=\mathbf{9 8}{ }^{*} \log [\text { non-fasting TG }](m g / d L)-\mathbf{1 8 2} \\
& \text { TRL-C } / \text { apoA-I }=\mathbf{8 . 1 5}(\log [\text { non-fasting TG }] / \text { HDL-C })-\mathbf{0 . 1 8}
\end{aligned}
$$

Practically, these equations allow for calculating TRL-C without bias from standard non-fasting lipids, depending on apoB $B_{100}$ availability (units $\mathrm{mg} / \mathrm{dL}$ ):

1. apo $B_{100}$ is available alongside standard non-fasting lipids:

$$
\begin{array}{r}
\text { TRL-C }=\mathbf{T C}-[(0.0106 * \mathbf{T C}-0.0036 * \mathbf{T G}+0.017 \\
\left.\left.* \mathbf{a p o B}_{100}-0.27\right) * 38.6\right]-\mathbf{H D L}-\mathbf{C}
\end{array}
$$

2. apo $B_{100}$ level is not available, and is computed according to [19]:

$$
\begin{aligned}
\text { TRL-C }=\text { TC- } & {[(0.0106 * \mathbf{T C}-0.0036 * \mathbf{T G}+0.017} \\
& *[0.65 *(\mathbf{T C}-\mathbf{H D L}-\mathbf{C})+6.3]-0.27) \\
& * 38.6]-\mathbf{H D L}-\mathbf{C}
\end{aligned}
$$

\section{Discussion}

Measuring TG represents an easy means to estimate the combined mass of fasting or non-fasting TRLs, as surrogate 

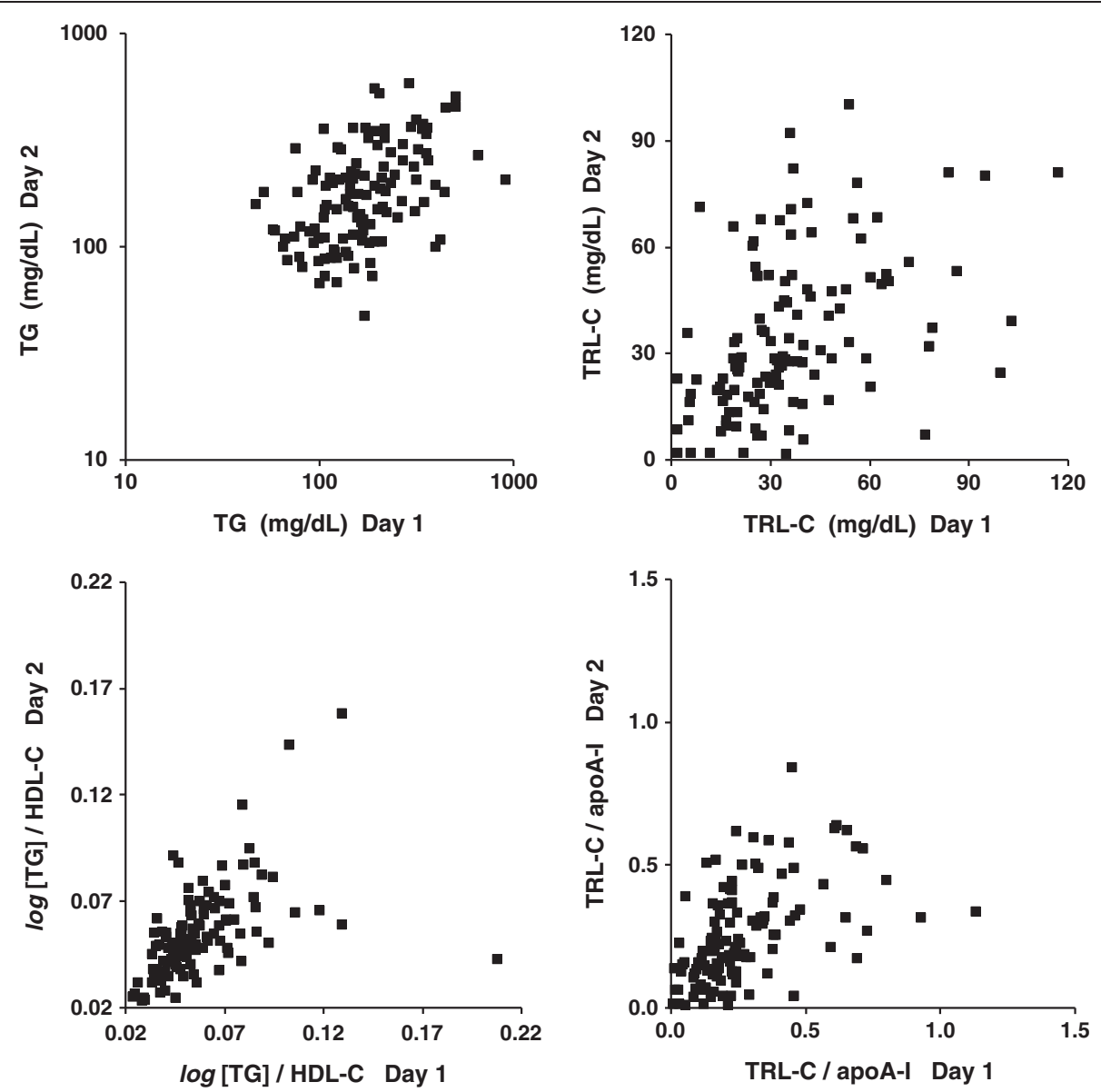

Figure 1 Plots of untransformed values obtained on day 1 ( $X$ axis) and day 2 ( $Y$ axis) for nonfasting triglycerides (TG) (upper left); TG-rich lipoprotein cholesterol (TRL-C) (upper right); nonfasting log [TG]/high-density lipoprotein cholesterol (HDL-C) (lower left); and TRL-C/apolipoprotein (apo) A-I (lower right) in 120 patients with type 2 diabetes.

for their cholesterol load. An excess of TRLs, including RLPs, throughout the nycthemeron epitomizes CMR conditions such the MetS, IR and the common form of T2DM. Elevated levels of TRL-C contribute, alongside LDL-C, to plaque formation and progression. TRL-C is a modifiable driver of RVR. Whereas TG as such are not atherogenic, the well-demonstrated association between fasting or non-fasting TG and CVD is underlied by the atherogenicity of TRLs, especially that of RLPs [2-6,8-11,32,33].

In fasting conditions, hypertriglyceridemia $>150 \mathrm{mg} / \mathrm{dL}$ is categorized as "elevated" VLDL, corresponding to TRL-C levels $>30 \mathrm{mg} / \mathrm{dL}$. Such assumption of equivalence is valid only if the composition of VLDL, in terms of C and TG, is in a ratio of $1 / 5$. This is not necessarily the case in CMR states where non-VLDL TRLs (among which

Table 3 Precision and discrimination of nonfasting TG, TRL-C, and atherogenic dyslipidemia ratios expressed as betweensubject Standard Deviations $\left(\mathrm{SD}_{\mathrm{u}}\right)$, global within subject Standard Deviation $\left(\mathrm{SD}_{\mathrm{w}}\right)$, Discriminant Ratio (DR), and measured Pearson's correlation coefficients between pairs of variables [adjusted for attenuation]

\begin{tabular}{lcccccc}
\hline & $\mathrm{SD}_{\mathbf{u}}$ & $\mathrm{SD}_{\mathbf{w}}$ & $\mathrm{DR}$ & $\mathrm{Cls}$ & $\boldsymbol{p}$ & Pearson's coefficient \\
\hline $\log [\mathrm{TG}]$ & $\mathbf{0 . 1 6 1}$ & $\mathbf{0 . 1 7 1}$ & $\mathbf{0 . 9 4}$ & {$[0.72-1.19]$} & 0.5604 & $\mathbf{0 . 9 2}$ \\
TRL-C & $\mathbf{1 5 . 2 0}$ & $\mathbf{1 8 . 0 6}$ & $\mathbf{0 . 8 4}$ & {$[0.61-1.09]$} & & {$[1.00]$} \\
$\log [\mathrm{TG}] / \mathrm{HDL}-\mathrm{C}$ & $\mathbf{0 . 0 1 9 8}$ & $\mathbf{0 . 0 1 9 5}$ & $\mathbf{1 . 0 1}$ & {$[0.79-1.27]$} & 0.0482 & $\mathbf{0 . 8 9}$ \\
TRL-C/apoA-I & $\mathbf{0 . 1 3 8}$ & $\mathbf{0 . 2 1 0}$ & $\mathbf{0 . 6 5}$ & {$[0.40-0.90]$} & & {$[1.00]$} \\
\hline
\end{tabular}

Values from nonfasting results of individual tests and means of their duplicates in 120 type 2 diabetes patients, with [2.5 - 97.5\%] confidence intervals (Cls) for DR's. Apo apolipoprotein, C cholesterol, HDL high-density lipoprotein, TG triglycerides, TRL TG-rich lipoprotein. P values represented the significancies of the differences between DRs of each pair of variables. For correlation between estimates, values were obtained from the mean of different measurements performed on separate days. 

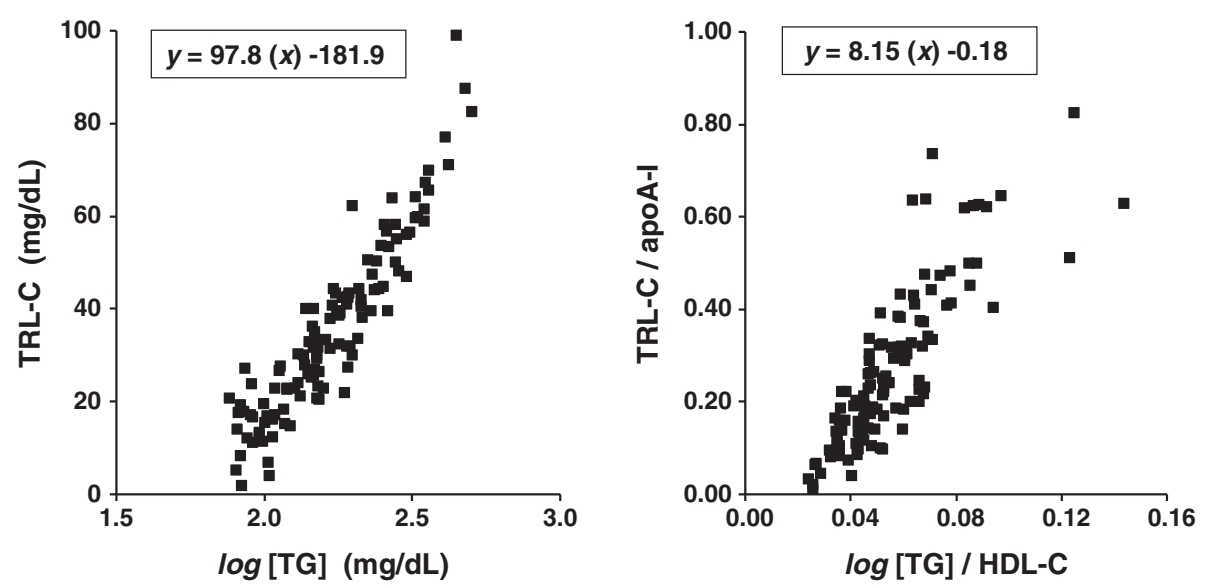

Figure 2 Equivalence between tests. Left panel: plots of untransformed values of log[triglycerides (TG)] ( $X$ axis) vs. TG-rich lipoprotein cholesterol (TRL-C) (Y axis). Right panel: plots of log[TG]/high-density lipoprotein cholesterol (HDL-C) ( $X$ axis) vs. TRL-C/apolipoprotein (apo) A-I (Y axis). The equations of the two unbiased lines of equivalence relating each pair of measurements are provided on the graphs. All values obtained from the means of nonfasting values measured on two different days in 120 patients with type 2 diabetes mellitus.

numerous RLPs) co-exist alongside VLDL. Likewise, in non-fasting conditions, TRLs are further heterogeneous, in size and composition, being populated by various TG-enriched and relatively TG-depleted lipoproteins (including remnants from the endogenous and exogenous pathways). The C/TG ratio of non-fasting TRLs substantially differs from that of fasting TRLs, the latter essentially consisting of standard VLDL with $20 \%$ cholesterol [1,3,13-17,20,21].

For this reason, recent articles on the usefulness of " $\mathrm{RC}$ " as residual risk marker relied by default on Friedewald's formula to estimate the LDL-C component of the equation. Doing so, their authors did not distinguish TRL-C from RC. Such an oversimplification ascribes to RC all the observed risk of non-fasting TRL-C. Besides, their rationale for extending the use of Friedewald's equation to determine LDL-C in non-fasting samples, in place of a direct assay, relied upon a linear relationship between calculated and measured LDL-C in a reference subgroup, such a relationship being a self-fulfilling prophecy $[8,10,11,14]$.

The present results provide unbiased and physiologicallyconsistent equations to determine TRL-C from nonfasting lipids, regardless apo $\mathrm{B}_{100}$ availability. As expected, non-fasting TRL-C and $\log [\mathrm{TG}]$ were highly correlated, with adjusted Pearson's coefficient reaching unity. Since both measures have uniform precision and discrimination, they provide similar information for ranking patients according to non-fasting TRLs, and are interchangeable. Yet, conceptually and educationally, determining TRL-C as surrogate for TRLs is more attractive, since it quantifies the atherogenic component directly involved in driving $\mathrm{CV}$ risk, including all the cholesterol load from RLPs. In this context, the DR method provides an unbiased equivalence equation allowing to predict TRL-C from $\log$ [TG], or vice-versa.

While the concept of low HDL-C as unconditional RF is strongly debated, the coexistence of elevated fasting TG together with low fasting HDL-C allows identifying patients with $\mathrm{AD}$, in whom residual risk is particularly high, even when on-statin LDL-C is controlled [28-30,33,34]. An explanation for the accrued RVR from AD in the fasting state is that it could be a marker for high numbers of postprandial TRLs and elevated non-fasting TRL-C. This is supported by results from an ACCORD-Lipid substudy, in which fenofibrate similarly lowered non-fasting TG in all T2DM participants, while reducing postprandial $\mathrm{apoB}_{48}$ excursions only in individuals with elevated fasting TG at baseline, a subgroup in which fenofibrate reduced CV outcomes [35].

In the presence of fasting hypertriglyceridemia $(>150$ $\mathrm{mg} / \mathrm{dL})$, the HDL-C cutoffs defining $\mathrm{AD}(\leq 40 \mathrm{mg} / \mathrm{dL}$ [men] and $\leq 50 \mathrm{mg} / \mathrm{dL}$ [women]) are transposable to nonfasting conditions, because remnant TRLs have little influence on HDL-C. Contrariwise, there are currently no standards or agreement defining (i) the upper physiological value for non-fasting TG; (ii) the sampling time after meal; and (iii) the lipid content and composition of the previous meal. For all these reasons we suggest to use either [TRL-C/apoA-I] or $[\log [\mathrm{TG}] / \mathrm{HDL}-\mathrm{C}]$ to assess postprandial $\mathrm{AD}$ as a continuous variable.

As the underlying correlation between TRL-C and $\log$ [TG] on one hand, and between TRL-C/apoA-I and $\log$ [TG]/HDL-C on the other hand, reached unity once pre-analytical and analytical attenuation were taken into account, these two approaches may be used interchangeably to assess equivalent biological measures. While 
there was no significant difference between the discriminating performance of $\log [\mathrm{TG}]$ compared to TRL-C, the discrimination of the ratio $\log [(\mathrm{TG}] / \mathrm{HDL}-\mathrm{C}$ was clearly and significantly higher than the TRL-C/apoA-I ratio to quantify the severity of non-fasting $\mathrm{AD}$ in patients at high CMR. Given the perfect concordance between pairs of measurements, the clinician may prefer to expressing $\mathrm{CV}$ risk linked to TRL-C (intuitively more educational than $\log [\mathrm{TG}])$, and to determine $\mathrm{CV}$ risk related to $\mathrm{AD}$ by calculating $\log [\mathrm{TG}] / \mathrm{HDL}-\mathrm{C}$, which is superior to TRL-C/apoA-I. The latter has the inconvenience to require apoA-I determination on top of routine lipids. Regarding biometric equivalence between atherogenicantiatherogenic ratios, we previously reported that nonHDL-C/HDL-C provides CV risk stratification similar to the apoB $B_{100} /$ apoA-I ratio [36].

In this study, the performance of the above measures to that of a direct measurement of RC was not assessed, since the latter is not part of routine risk assessment. As regards cohort's size, we compared the performance of two means to assess the burden of atherogenic TRL in 120 patients, an ample number given the DR methodology, which only requires $\geq 20$ samples with 2 replicates as long as they represent a clinically-meaningful range for the variable under study [see Appendix of [22] for a detailed discussion on sample size requirements for estimating DRs]. The fact that patients had T2DM in this study does not limit the applicability of the findings, since the metabolic and pathophysiological fundamentals of TRL, CMR and RC are similar in diabetic and nondiabetic subjects, at increasing levels along a continuum, from normal to impaired fasting glucose, and from prediabetes to T2DM $[37,38]$.

In conclusion, estimating TRL-C requires formulas which reflect the complex compositional changes in nonfasting TRLs, the latter consisting of particles not exclusively generated along the VLDL pathway, in which TG-content is heterogeneous and changes dynamically. We provide two unbiased equations to estimate the burden of TRL-C based on routine nonfasting lipids, depending on apo $B_{100}$ measurement availability. Our results show that TRL-C and $\log [\mathrm{TG}]$ are as effective and interchangeable to assess the atherogenic load of nonfasting TRLs. However, to grade TRL-related AD, it is better to use $\log [\mathrm{TG}] / \mathrm{HDL}-\mathrm{C}$, which is inherently superior to TRL-C/ apoA-I, while measuring the same underlying variable.

\section{Competing interest}

The authors declare that they have no competing interest.

\section{Authors' contribution}

All authors have read and approved the manuscript.

\section{Author details}

${ }^{1}$ Division of Endocrinology \& Nutrition, Cliniques universitaires St-Luc and Institut de Recherche Expérimentale et Clinique (IREC), Université catholique de Louvain, Brussels, Belgium. ²Division of Cardiology, Cliniques universitaires St-Luc and Pôle de Recherche Cardiovasculaire, Institut de Recherche Expérimentale et Clinique (IREC), Université catholique de Louvain, Brussels, Belgium. ${ }^{3}$ DipNatSci DipEarthSci DipGeogEnv PGCert (SocSc), Endocrinology \& Nutrition, UCL 54.74 Tour Claude Bernard +1, avenue Hippocrate 54, Brussels B-1200, Belgium.

Received: 20 December 2013 Accepted: 19 February 2014 Published: 10 March 2014

\section{References}

1. Cohn JS, Marcoux C, Davignon J: Detection, quantification, and characterization of potentially atherogenic triglyceride-rich remnant lipoproteins. Arterioscler Thromb Vasc Biol 1999, 19:2474-2486.

2. Brunzell JD, Davidson M, Furberg CD, Goldberg RB, Howard BV, Stein JH, Witztum JL: American Diabetes Association; American College of Cardiology foundation. Lipoprotein management in patients with cardiometabolic risk. Consensus statement from the American Diabetes Association and the American College of Cardiology foundation. Diabetes Care 2008, 31:811-822.

3. Fujioka $Y$, Ishikawa $Y$ : Remnant lipoproteins as strong key particles to atherogenesis. J Atheroscler Thromb 2009, 16:145-154.

4. Kannel WB, Vasan RS: Triglycerides as vascular risk factors: new epidemiologic insights. Curr Opin Cardiol 2009, 24:345-350.

5. Hermans MP, Fruchart JC: Reducing residual vascular risk in patients with atherogenic dyslipidaemia: where do we go from here? Clin Lipidol 2010, 5:811-826.

6. Triglyceride Coronary Disease Genetics Consortium and Emerging Risk Factors Collaboration, Sarwar N, Sandhu MS, Ricketts SL, Butterworth AS, Di Angelantonio E, Boekholdt SM, Ouwehand W, Watkins H, Samani NJ, Saleheen D, Lawlor D, Reilly MP, Hingorani AD, Talmud PJ, Danesh J: Triglyceride-mediated pathways and coronary disease: collaborative analysis of 101 studies. Lancet 2010, 375:1634-1639.

7. Jacobson TA: Opening a new lipid "apo-thecary": incorporating apolipoproteins as potential risk factors and treatment targets to reduce cardiovascular risk. Mayo Clin Proc 2011, 86:762-780.

8. Langsted A, Freiberg JJ, Tybjaerg-Hansen A, Schnohr P, Jensen GB, Nordestgaard BG: Non-fasting cholesterol and triglycerides and association with risk of myocardial infarction and total mortality: the Copenhagen City heart study with 31 years of follow-up. J Intern Med 2011, 270:65-75.

9. Jørgensen AB, Frikke-Schmidt R, West AS, Grande P, Nordestgaard BG, Tybjærg-Hansen A: Genetically elevated non-fasting triglycerides and calculated remnant cholesterol as causal risk factors for myocardial infarction. Eur Heart J 2013, 34:1826-1833.

10. McPherson R: Remnant cholesterol: "Non- $(\mathrm{HDL}-\mathrm{C}+\mathrm{LDL}-\mathrm{C})$ " as a coronary artery disease risk factor. J Am Coll Cardiol 2013, 61:437-439.

11. Varbo A, Benn M, Tybjærg-Hansen A, Jørgensen AB, Frikke-Schmidt $R$, Nordestgaard BG: Remnant cholesterol as a causal risk factor for ischemic heart disease. J Am Coll Cardiol 2013, 61:427-436.

12. Zambon A, Puato M, Faggin E, Grego F, Rattazzi M, Pauletto P: Lipoprotein remnants and dense LDL are associated with features of unstable carotid plaque: a flag for non-HDL-C. Atherosclerosis 2013, 230:106-109.

13. Fruchart JC, Duriez P: HDL and triglyceride as therapeutic targets. Curr Opin Lipidol 2002, 13:605-616.

14. Friedewald WT, Levy Rl, Fredrickson DS: Estimation of the concentration of low-density lipoprotein cholesterol in plasma, without use of the preparative ultracentrifuge. Clin Chem 1972, 18:499-502.

15. Martin SS, Blaha MJ, Toth PP, Joshi PH, McEvoy JW, Ahmed HM, Elshazly MB, Swiger KJ, Michos ED, Kwiterovich PO, Kulkarni KR, Chimera J, Cannon CP, Blumenthal RS, Jones SR: Very large database of lipids: rationale and design. Clin Cardiol 2013, 36:641-648.

16. Martin SS, Blaha MJ, Elshazly MB, Toth PP, Kwiterovich PO, Blumenthal RS, Jones SR: Comparison of a novel method vs the friedewald equation for estimating low-density lipoprotein cholesterol levels from the standard lipid profile. JAMA 2013, 310:2061-2068.

17. Planella T, Cortés M, Martínez-Brú C, González-Sastre F, Ordóñez-Llanos J: Calculation of LDL-cholesterol by using apolipoprotein B for classification of nonchylomicronemic dyslipemia. Clin Chem 1997, 43:808-815.

18. Björkegren J, Karpe F, Milne RW, Hamsten A: Differences in apolipoprotein and lipid composition between human chylomicron remnants and very 
low density lipoproteins isolated from fasting and postprandial plasma. J Lipid Res 1998, 39:1412-1420.

19. Hermans MP, Sacks FM, Ahn SA, Rousseau MF: Non-HDL-cholesterol as valid surrogate to apolipoprotein $B_{100}$ measurement in diabetes: discriminant Ratio and unbiased equivalence. Cardiovasc Diabetol 2011, 10:20.

20. Bairaktari E, Hatzidimou K, Tzallas C, Vini M, Katsaraki A, Tselepis A, Elisaf M, Tsolas O: Estimation of LDL cholesterol based on the friedewald formula and on apo B levels. Clin Biochem 2000, 33:549-555.

21. Martin SS, Blaha MJ, Elshazly MB, Brinton EA, Toth PP, McEvoy JW, Joshi PH Kulkarni KR, Mize PD, Kwiterovich PO, Defilippis AP, Blumenthal RS, Jones SR: Friedewald-estimated versus directly measured low-density lipoprotein cholesterol and treatment implications. J Am Coll Cardiol 2013, 62:732-739.

22. Levy JC, Morris RJ, Hammersley M, Turner RC: Discrimination, adjusted correlation, and equivalence of imprecise tests: application to glucose tolerance. Am J Physiol 1999, 276:E365-E375.

23. Hermans MP, Levy JC, Morris RJ, Turner RC: Comparison of insulin sensitivity tests across a range of glucose tolerance form normal to diabetes. Diabetologia 1999, 42:678-687.

24. Alberti KG, Eckel RH, Grundy SM, Zimmet PZ, Cleeman Jl, Donato KA, Fruchart JC, James WP, Loria CM, Smith SC Jr: International Diabetes Federation Task Force on Epidemiology and Prevention; National Heart, Lung, and Blood Institute; American Heart Association; World Heart Federation; International Atherosclerosis Society; International Association for the Study of Obesity. Harmonizing the metabolic syndrome: a joint interim statement of the International Diabetes Federation Task Force on Epidemiology and Prevention; National Heart, Lung, and Blood Institute; American Heart Association; World Heart Federation; International Atherosclerosis Society; and International Association for the Study of Obesity. Circulation 2009, 120:1640-1645.

25. Levey AS, Bosch JP, Lewis JB, Greene T, Rogers N, Roth D: A more accurate method to estimate glomerular filtration rate from serum creatinine: $A$ new prediction equation. Modification of diet in renal disease study group. Ann Intern Med 1999, 130:461-470.

26. Hermans MP, Ahn SA, Rousseau MF: The multi-faceted outcomes of conjunct diabetes and cardiovascular familial history in type 2 diabetes. J Diabetes Complications 2012, 26:187-194.

27. Kothari V, Stevens RJ, Adler Al, Stratton IM, Manley SE, Neil HA, Holman RR: UKPDS 60: risk of stroke in type 2 diabetes estimated by the UK Prospective diabetes study risk engine. Stroke 2002, 33:1776-1781.

28. Hermans MP, Ahn SA, Rousseau MF: $\log (\mathrm{TG}) / \mathrm{HDL}-\mathrm{C}$ is related to both residual cardiometabolic risk and $\beta$-cell function loss in type 2 diabetes males. Cardiovasc Diabetol 2010, 9:88.

29. Hermans MP, Ahn SA, Rousseau MF: The atherogenic dyslipidemia ratio $[\log (\mathrm{TG}) / \mathrm{HDL}-\mathrm{C}]$ is associated with residual vascular risk, $\beta$-cell function loss and microangiopathy in type 2 diabetes females. Lipids Health Dis 2012, 11:132.

30. Querton L, Buysschaert M, Hermans MP: Hypertriglyceridemia and residual dyslipidemia in statin-treated, patients with diabetes at the highest risk for cardiovascular disease and achieving very-low low-density lipoprotein-cholesterol levels. J Clin Lipidol 2012, 6:434-442.

31. Murase T, Okubo M, Takeuchi I: Non-HDL-cholesterol/apolipoprotein B ratio: a useful distinguishing feature in the screening for type III hyperlipoproteinemia. J Clin Lipidol 2010, 4:99-104.

32. Hermans MP, Ahn SA, Rousseau MF, Zimering MB: Residual vascular risk in T2DM: the next frontier. In Recent Advances in the Pathogenesis, Prevention and Management of Type 2 Diabetes and its Complications. Rijeka (Croatia): Intech; 2011:45-66.

33. Bestehorn K, Smolka W, Pittrow D, Schulte H, Assmann G: Atherogenic dyslipidemia as evidenced by the lipid triad: prevalence and associated risk in statin-treated patients in ambulatory care. Curr Med Res Opin 2010, 26:2833-2839

34. Fruchart JC, Sacks FM, Hermans MP: International Steering Committee of $R$ (3)i. Implications of the ACCORD lipid study: perspective from the Residual Risk Reduction Initiative (R(3)i). Curr Med Res Opin 2010, 26:1793-1797.

35. Reyes-Soffer G, Ngai Cl, Lovato L, Karmally W, Ramakrishnan R, Holleran S, Ginsberg HN: Effect of combination therapy with fenofibrate and simvastatin on postprandial lipemia in the ACCORD lipid trial. Diabetes Care 2013, 36:422-428
36. Hermans MP, Ahn SA, Rousseau MF: The non-HDL-C/HDL-C ratio provides cardiovascular risk stratification similar to the $\mathrm{ApoB} / \mathrm{ApoA} 1$ ratio in diabetics: Comparison with reference lipid markers. Diabetes Metab Syndr 2007, 1:23-28

37. Tenenbaum A, Fisman EZ: Fibrates are an essential part of modern antidyslipidemic arsenal: spotlight on atherogenic dyslipidemia and residual risk reduction. Cardiovasc Diabetol 2012, 11:125.

38. Fruchart JC, Davignon J, Hermans MP, Al-Rubeaan K, Amarenco P, Assmann G, Barter P, Betteridge J, Bruckert E, Cuevas A, Farnier M, Ferrannini E, Fioretto P, Genest J, Ginsberg HN, Gotto AM Jr, Hu D, Kadowaki T, Kodama T, Krempf M, Matsuzawa Y, Núñez-Cortés JM, Monfil CC, Ogawa H, Plutzky J, Rader DJ, Sadikot S, Santos RD, Shlyakhto E, Sritara P, Sy R, Tall A, Tan CE, Tokgözoğlu L, Toth PP, Valensi P, Wanner C, Zambon A, Zhu J, Zimmet P: Residual risk reduction initiative (R3i). Residual macrovascular risk in 2013: what have we learned? Cardiovasc Diabetol 2014, 13:26.

doi:10.1186/1475-2840-13-56

Cite this article as: Hermans et al:: Novel unbiased equations to calculate triglyceride-rich lipoprotein cholesterol from routine non-fasting lipids. Cardiovascular Diabetology 2014 13:56.

\section{Submit your next manuscript to BioMed Central and take full advantage of:}

- Convenient online submission

- Thorough peer review

- No space constraints or color figure charges

- Immediate publication on acceptance

- Inclusion in PubMed, CAS, Scopus and Google Scholar

- Research which is freely available for redistribution 